\title{
Economic ageing and demographic change
}

\author{
Dominik Grafenhofer, Christian Jaag, Christian Keuschnigg and Mirela \\ Keuschnigg*
}

\begin{abstract}
This paper presents a generalised model of overlapping generations with economic ageing of households. Economic age is defined as a set of personal attributes such as earnings potential and tastes that are characteristic of a person's position in the life-cycle. We separate the concepts of economic age and time since birth by assuming only a small number of different states of age. Agents sharing the same economic characteristics are aggregated analytically to a small number of age groups. The model thus allows for a very parsimonious approximation of life-cycle differences in earnings, wealth and consumption. As an illustration, we apply the model quantitatively to study the impact of demographic change.
\end{abstract}

Keywords: Overlapping generations, ageing, demographic change, life-cycle. JEL-Classification: D58, D91, H55, J21.

\section{Introduction}

Modelling the behaviour of overlapping generations (OLG) of households is important for an understanding of many topics in the fields of fiscal policy and intertemporal macroeconomics. Depending on the particular issues to be analysed, economists have a range of models at hand. At one extreme is the representative agent model of infinitely lived consumers based on Ramsey (1928), Cass (1965), Koopmans (1965), and Weil (1987). At the other end is the two period OLG

\footnotetext{
* Dominik Grafenhofer, University of Toulouse, dominik@grafenhofer.at

Christian Keuschnigg (author of correspondence), University of St.Gallen, IFF-HSG, Varnbuelstrasse 19, CH-9000 St.Gallen, Email: christian.keuschnigg@unisg.ch

Christian Jaag, University of St.Gallen and Swiss Post, christian.jaag@post.ch

Mirela Keuschnigg, University of St.Gallen, mirela.keuschnigg@unisg.ch
} 
model pioneered by Samuelson (1958) and Diamond (1965). The model is analytically very tractable but cuts down life-cycle detail to the bare bones. The length of a period featuring constant interest rates and constant rates of consumption etc. covers about thirty years in real time, which imposes severe limits in quantitative empirical applications. At the expense of analytical tractability, empirical applications thus rely on numerically solved models with a large number of generations and detailed life-cycle patterns of earnings, consumption and savings. These models were pioneered by Auerbach and Kotlikoff (1987) and Hubbard and Judd (1987) for the analysis of tax and fiscal policy including demographic change and social security reform.

Life-cycle models with many generations tend to be analytically intractable and must be solved numerically. Even the simplest life-cycle model with 55 cohorts operates in a state space of as many as 108 dimensions, as Laitner (1990) has shown. Dimensions explode if one adds additional structure and household sector heterogeneity such as human capital accumulation, different skill groups, several countries etc. By way of contrast, the perpetual youth model based on Yaari (1965), Blanchard (1985) and Buiter (1988) is an analytically very tractable OLG model with a realistic period length. The main drawback, however, is the rigid demographic assumption of an age independent mortality rate and the absence of life-cycle detail of earnings, consumption and savings. ${ }^{1}$ For this reason, the model is not well suited for the analysis of ageing, old age insurance and other applications where it is necessary to distinguish households by age groups. The recent extension by Gertler (1999) reconciles the perpetual youth model with an important aspect of life-cycle behaviour by allowing for a stochastic transition from work to retirement and from retirement to death. It thereby opens up useful applications with a model that includes no more than two stock variables to represent the household sector. Although more complex, it is analytically tractable and easily implemented empirically. However, it does not allow any further disaggregation between different age groups of workers and retirees. $^{2}$

This paper presents an alternative approach that retains the simplicity of analytically aggregated OLG models and yet succeeds in approximating the rich life-cycle detail of the high dimensional finite horizon models. The number of state variables is drastically reduced, depending on the desired degree of approximation. The key idea is to separate the concept of "economic age" from

Heijdra and Romp (2005), however, managed to include some life-cycle features in a continuous time version of the model that still allows for analytical solutions.

2 This decomposition is essential for many applications, see Jaag, Keuschnigg and Keuschnigg (2007), for example. 
"time since birth". We understand economic age as a set of physical or mental attributes such as earnings potential, mortality, tastes and other characteristics. They are retained over several periods before agents move to the next age state. This is the key difference to existing models where ageing and the passing of time are perfectly synchronised and age is understood as time since birth. In introducing the concept of economic age, we are thus able to introduce an approximate life-cycle structure with a much reduced number of state variables and yet retain a period length of one year for realistic short-run and transitional dynamics.

With economic ageing, people move stochastically from one age state to another with an age group specific transition rate. All agents sharing the same economic characteristics are analytically aggregated in the same age group. Our model is thus a natural generalisation of Gertler (1999). Gertler aggregates into two age groups, workers and retirees. However, for many applications it is necessary to distinguish several worker groups to capture life-cycle earnings detail, and also a few groups of retirees to take account of the substantial heterogeneity among old and very old generations. Our generalised OLG model allows for considerably more heterogeneity and thus achieves a much closer approximation of empirical life-cycle properties. In this paper, we distinguish eight age (life-cycle) groups and choose the economic characteristics to correspond to the average data of people in their twenties, thirties etc. Another extension relative to Gertler is that we also allow for mortality in younger age states for a closer approximation to the demographic composition of the population. In fact, the number of age groups, and thereby the degree of life-cycle approximation, can be chosen variably. Our generalised life-cycle model is thus able to replicate a wide range of intertemporal household models as special cases by appropriately choosing the parameters governing the mortality and ageing process. ${ }^{3}$ In the limit, when increasing the number of age states until they are equal to the number of life-cycle periods, our model becomes identical to the Auerbach Kotlikoff (1987) model.

The main purpose of this paper is to introduce the concept of economic age in a generalised OLG model. We illustrate its application by analysing two scenarios of demographic change: a temporary baby boom and increasing life expectancy leading to a substantial ageing of the population. The paper is organised as follows. Section 2 explains how an agent's life-cycle is approximated by defining an arbitrary number of age states with different economic characteristics. We then

3 This is shown in the extended discussion paper version in Grafenhofer et al. (2006). The discussion paper contains all proofs which are partly omitted in this paper, and it applies the model to stylised pension reform rather than demographic change. 
show how all agents sharing the same economic age are analytically aggregated into a single life-cycle group. Section 3 solves the intertemporal optimisation problem of households in the presence of mortality and ageing risks and sets up the dynamic general equilibrium model with demographic structure. Henceforth, we use EA as shorthand for the economic ageing model. Section 4 presents two illustrative empirical scenarios of demographic change, and Section 5 sets out our conclusions.

\section{A model of economic ageing}

Age is commonly associated with time since birth. In standard life-cycle models, age characteristics such as labour productivity, mortality, health and other individual attributes change from period to period so that there are as many states of age as there are life-cycle periods. To reduce the state space, we approximate the life-cycle by a small number of different states of "economic age", $a \in(1, \ldots, A)$.

In this paper, we describe economic age as a vector of attributes $\left(\theta^{a}, \gamma^{a}, \omega^{a}\right)$, consisting of labour productivity $\theta^{a}$, the probability $\gamma^{a}$ of not dying, i.e., of surviving to the next period, and the probability $\omega^{a}$ of not ageing, i.e., of remaining in the same state of economic age. These characteristics change only when an agent switches to the next stage of economic age. Economic ageing is a discrete event that occurs stochastically and irregularly. Agents may thus retain their state of economic age for several periods before they switch to the next age state. We thus need two different clocks to measure the passing of real time since birth and the speed of economic ageing. The latter is determined by the probability $\omega^{a}$. We measure real time in regular annual periods, with interest, prices and quantities appropriately defined per year. The ageing clock runs slower and stochastically. With $\omega=1$ agents would age from period to period so that economic and demographic ageing would coincide.

\subsection{Life-cycle histories}

We define a discrete number of $A$ states of economic age. Each state is characterised by a given set of life-cycle characteristics. Age group $a \in(1, \ldots, A)$ collects all agents sharing the same economic characteristics. People start life in state $a=1$ with a given set of attributes. An agent changes her life-cycle characteristics only when moving to the next state of age $a+1$. Since economic ageing occurs less frequently than true ageing as measured by time since birth, 
households differ not only by their date of birth, but also by their diverse lifecycle histories. An agent's life-cycle history is her biography of economic ageing events that have happened since birth. It is represented by a vector $\alpha$ that records the past dates of ageing events when the agent has moved from one to the next state. At date $t$, the set of possible histories of a household belonging to age group $a$ is

$$
\mathrm{N}_{t}^{a} \equiv\left\{\left(\alpha_{1}, \ldots, \alpha_{a}\right): \alpha_{1}<\ldots<\alpha_{a} \leq t\right\} .
$$

A particular life-cycle history is represented by a vector $\alpha=\left(\alpha_{1}, \ldots, \alpha_{a}\right) \in \mathbf{N}_{t}{ }^{a}$. The element $\alpha_{i}$ denotes the date at which the household that was formerly in age group $i-1$, became a member of group $i$. The element $\alpha_{1}$ thus lists the date of birth. We say that a member of group one aged only once with no further ageing since birth. Nevertheless, different persons of the first age group are heterogeneous since they were born at different moments in the past. The set of possible biographies is $\mathrm{N}_{t}^{1}=\left\{\left(\alpha_{1}\right): \alpha_{1} \leq t\right\}$. By the same logic, $\alpha_{2}$ is the date when an agent moved from group 1 into 2. People in age group 2 have aged twice. The set of life-cycle histories in this case is $\mathbf{N}_{t}^{2}=\left\{\left(\alpha_{1}, \alpha_{2}\right): \alpha_{1}<\alpha_{2} \leq t\right\}$. By definition, a person belonging to group $a$ has aged $a$ times in total. Her biography given by the vector $\alpha$ thus contains $a$ elements.

Economic ageing is assumed to occur infrequently and stochastically, implying that agents spend variable lengths of time in a given age state. At any moment in time, an individual with an arbitrarily given life-cycle history faces the risk of economic ageing and dying. She must reckon with three possible events: (i) she will die with probability $1-\gamma^{a}$; (ii) she will survive without ageing and remain in the same age group with probability $\gamma^{a} \omega^{a}$, and (iii) she will survive and age and belong to age group $a+1$ next period with probability $\gamma^{a}\left(1-\omega^{a}\right)$. A key assumption is that these transition probabilities are identically and independently distributed among all agents in group $a$. They are thus the same for all agents, independent of how long they have already been in this age state. Individuals in the last age group have exhausted the ageing process and remain in this group with probability one, $\omega^{A}=1$. They may either survive with probability $\gamma^{A}$ within group $A$ or die with probability $1-\gamma^{A}$. It should be noted that only the last age group behaves according to the mortality and demographic assumptions of Blanchard's (1985) perpetual youth model.

Since economic characteristics differ across age groups, an agent's consumption, assets and other economic variables will generally depend on her particular life-cycle history, which reflects how long she stayed in any of the past states of economic age. For example, assets depend on the agent's past earnings 
history which, in turn, is linked to her ageing trajectory. To keep track of the population's heterogeneity, each agent must thus be very carefully identified by her age group as well as her ageing biography $\alpha$. The number of agents at date $t$, in state of life $a$ and with the same ageing history $\alpha$ is given by $N_{\alpha, t}^{a}$. People with the same biography are identical so that $N_{\alpha, t}^{a}$ is the smallest homogeneous population unit. They all face the same independent probability of moving to one of the next, alternative states. With stochastically independent risks, the law of large numbers applies so that the individual probabilities stated above correspond to the fraction of people subject to the same demographic shock. Consequently, the group is divided into three subgroups next period: (i) those who die and whose biography is updated to $\alpha^{\dagger}$ where $\dagger$ means exit from the population; (ii) those who survive within the same age group $a$, and their biography remains unchanged; and (iii) those who are hit by an ageing event and switch to the next higher age group:

$$
\begin{array}{llll}
\text { (i) } N_{\alpha^{\dagger}, t+1}^{\dagger} & =N_{\alpha, t}^{a} \cdot\left(1-\gamma^{a}\right), & & \text { death, } \\
\text { (ii) } N_{\alpha, t+1}^{a} & =N_{\alpha, t}^{a} \cdot \gamma^{a} \omega^{a}, & & \text { no aging, } \\
\text { (iii) } N_{\alpha^{\prime}, t+1}^{a+1} & =N_{\alpha, t}^{a} \cdot \gamma^{a}\left(1-\omega^{a}\right), & & \text { aging. }
\end{array}
$$

The last line refers to persons with biography $\alpha=\left\{\alpha_{1}, \ldots, \alpha_{a}\right\} \in \mathrm{N}_{t}{ }^{a}$ who belong to age group $a$ and experience an ageing event in period $t$. These agents arrive in the next age state $a+1$ next period. Their biography is thus appended by a new entry $t+1$ and reads $\alpha^{\prime}=\left(\alpha_{1}, \ldots, \alpha_{a}, t+1\right) \in \mathrm{N}_{t+1}^{a+1}$. The set of agents $\mathrm{N}_{t+1}^{a+1}$ in group $a+1$ can thus be decomposed into two subsets: the first consists of all those agents who already belonged to group $a+1$ in period $t$ and whose biography $\alpha$ remains unchanged, as in case (ii) above referring to group $a$. The second subset refers to the new arrivals with a freshly appended biography $\alpha^{\prime}$. This decomposition into movers and stayers becomes important for analytical aggregation below. ${ }^{4}$

4 The perspective in (2) is from period $t$ to the next period and therefore distinguish between those who stay and who leave age group $a$. The alternative perspective is from $t+1$ by distinguishing the incumbants (stayers) who already belonged to group $a$ in the preperiod, (ii): $N_{\alpha, t+1}^{a}=N_{\alpha, t}^{a} \cdot \gamma^{a} \omega^{a}$, and the new arrivals (movers) who belonged to group $a-1$ in $t$, (iii): $N_{\alpha^{\prime}, t+1}^{a}=N_{\alpha, t}^{a-1} \cdot \gamma^{a-1}\left(1-\omega^{a-1}\right)$. 


\subsection{Aggregate demographics}

The total number of agents in the same economic demographic state $a$ is obtained by adding all possible histories $\alpha$ that end up in state $a$,

$$
N_{t}^{a} \equiv \sum_{\alpha \in \mathrm{N}_{t}^{a}} N_{\alpha, t}^{a} .
$$

The stochastic arrival of ageing events implies that agents currently alive have spent variable lengths of time in each preceding age state since birth. In consequence, many different ageing trajectories lead to the same age state in period $t$. The aggregation formula takes the sum over all possible biographies, including varying dates of birth, that could conceivably lead to age state $a$ in period $t$.

All agents in a given group are assumed in (2) to face identical transition probabilities. Given stochastically independent mortality and ageing risks, one can use the law of large numbers to analytically aggregate the population into separate age groups. These aggregates evolve deterministically over time. The result is

\section{Proposition 1:}

(a) The aggregate law of motion for age group $1<a \leq A$ is

$$
N_{t+1}^{a}=\gamma^{a} \omega^{a} \cdot N_{t}^{a}+\gamma^{a-1}\left(1-\omega^{a-1}\right) \cdot N_{t}^{a-1}, \quad \omega^{A}=1 .
$$

(b) Age group 1 evolves according to

$$
N_{t+1}^{1} \quad=\gamma^{1} \omega^{1} \cdot N_{t}^{1}+n_{t}, \quad n_{t} \equiv N_{(t+1), t+1}^{1} \quad \text { newborns. }
$$

(c) The total population grows by

$$
N_{t+1}=N_{t}+n_{t}-\sum_{a}\left(1-\gamma^{a}\right) N_{t}^{a}, \quad N_{t} \equiv \sum_{a} N_{t}^{a} .
$$

Proof: The smallest homogeneous population unit is $N_{\alpha, t}^{a}$. It is assumed to be large enough that the law of large numbers applies. As indicated in (2), $N_{\alpha, t}^{a}$ breaks down into three groups. Members of group $a$ can either die, or stay in the same group, or move to group $a+1$ next period. Conversely, agents in group $a$ next period come from stayers $\alpha \in \mathbf{N}_{t}{ }^{a}$ and movers from the preceding group $\mathbf{N}_{t}^{a-1}$. Obviously, a stayer remains in the same group $a$ next period, $\alpha \in \mathbf{N}_{t+1}^{a}$, while a mover belongs to $\mathbf{N}_{t}{ }^{a-1}$ this period and $\mathbf{N}_{t+1}^{a}$ next period. A new entry $t+1$ is made in a mover's biography, $\alpha^{\prime}=\left\{\alpha_{1}, \ldots, \alpha_{a-1}, t+1\right\}$. Group $a$ next period is populated by agents with biographies $\alpha \in \mathrm{N}_{t+1}^{a}$. By definition, it can be broken down into incumbents with biographies $\alpha \in \mathbf{N}_{t}{ }^{a}$, and new arrivals with biographies $\alpha^{\prime}=(\alpha, t+1)$ where $\alpha^{\prime} \in \mathbf{N}_{t+1}^{a}$ and $\alpha \in \mathrm{N}_{t}^{a-1}: \sum_{\alpha \in \mathrm{N}_{t+1}^{a}} N_{\alpha, t+1}^{a}=\sum_{\alpha \in \mathbf{N}_{t}^{a}} N_{\alpha, t+1}^{a}+\sum_{\alpha \in \mathrm{N}_{t}^{a-1}} N_{\alpha, t+1}^{a}$. Using (2), 


$$
\begin{aligned}
\sum_{\alpha \in \mathrm{N}_{t+1}^{a}} N_{\alpha, t+1}^{a} & =\sum_{\alpha \in \mathrm{N}_{t}{ }^{a}} \gamma^{a} \omega^{a} N_{\alpha, t}^{a}+\sum_{\alpha \in \mathrm{N}_{t}^{a-1}} \gamma^{a-1}\left(1-\omega^{a-1}\right) N_{\alpha, t}^{a-1}, \\
N_{t+1}^{a} & =\gamma^{a} \omega^{a} N_{t}^{a}+\gamma^{a-1}\left(1-\omega^{a-1}\right) N_{t}^{a-1} .
\end{aligned}
$$

Transition probabilities are identical for all members of the same group and independent of past history. They can thus be moved in front of the sum operators. Since the last group cannot age further, the event in (2.iii) is precluded, implying the restriction $\omega^{A}=1$. In the first group, the inflow is the number of newborns $n_{t}$ who start life with a biography $\alpha^{\prime}=(t+1)$. Adding (4-5) and noting the restriction $\omega^{A}=1$ yields (6).

The key demographic parameters are the birth rate, the transition rates to successive age groups, and the mortality rates. Since all are exogenous, the demographic subsystem is independent of economic influences and evolves autonomously according to (4-6). A stationary population requires that inflows and outflows of any age group must balance to yield constant group size. Using (4) and (5),

$$
N^{1}=\frac{n}{1-\gamma^{1} \omega^{1}}, \quad N^{a}=\frac{\gamma^{a-1}\left(1-\omega^{a-1}\right)}{1-\gamma^{a} \omega^{a}} \cdot N^{a-1}
$$

For any demographic transition, the exogenous driving force is the flow $n_{t}$ of newborns. With this flow being exogenously specified and constant, the system arrives at a stationary population $N$ with demographic structure as in (7).

\section{Life-cycle economies}

The theory of economic ageing is now combined with an intertemporal general equilibrium model with life-cycle decisions and perfect foresight. In economic applications, a key distinction between age groups is the definition of wagerelated income,

$$
y_{t}^{a}=\left\{\begin{array}{l}
\left(1-t^{w}\right) w_{t} \theta^{a}: \mathrm{a} \in\left\{1, \ldots, a^{R}-1\right\}, \\
p_{t}: \mathrm{a} \in\left\{a^{R}, \ldots, A\right\} .
\end{array}\right.
$$

There are several states of work and retirement life where $a^{R}$ denotes the first age state of retirement. Each worker in group $a$ is endowed with $\theta^{a}$ efficiency units of labour which earn a wage of $w_{t}$ per unit. Consequently, a worker's gross wage per unit of labour is $w_{t}^{a}=w_{t} \theta_{t}^{a}$. The government levies a proportional wage tax $t^{W}$ to finance pensions and other public spending. Retirees receive a pension of $p_{t}$ per capita from a pay-as-you-go (PAYG) social security system. Wage-related income per capita, $y_{t}^{a}$, differs across age groups due to varying 
labour productivity, but is identical for all agents within the same group. Importantly, it does not depend on life-cycle history $\alpha$ which is generally different for people in the same age group.

\subsection{The last age group}

With perfect foresight, today's decisions must anticipate the consequences for future income and welfare. To take account of this interdependency, we start with the last age group and solve the model backwards. The last group is conceptually different from earlier ones because no further ageing is possible $\left(\omega^{A}=1\right)$. Consequently, the set of possible events reduces to two. A person may either survive to the next period within the same age group, or die. The decisions of the last age group basically follow the principles of the perpetual youth model as in Blanchard (1985) albeit with one important difference. Since the last is only one of several age groups, average time spent in this group is rather limited. The mortality rate chosen must thus be much larger.

A member of the last age group is retired and receives an old age pension of $y_{t}^{A}=p_{t}$ per capita. Given current asset and pension income, agents choose consumption and savings and accumulate assets,

$$
\gamma^{A} A_{\alpha, t+1}^{A}=R_{t+1}\left[A_{\alpha, t}^{A}+y_{t}^{A}-C_{\alpha, t}^{A}\right],
$$

where $C$ stands for consumption, $A$ for assets, and $R=r+1$ for the interest factor equal to one plus the annual interest rate. The value of assets is measured at the end of the period and earns, together with new savings $y-C$, an interest $r_{t+1}$ until the end of the next period. The term $\gamma^{A}$ on the left-hand side is due to the assumption of reverse life insurance. The agent wants to be compensated during her lifetime for any accidental bequests that she leaves upon death. Such compensation is assumed to be available from a competitive insurance sector. The same demand for insurance arises for any age group. Suppose an agent has assets of $S_{\alpha, t}^{a}$ at the end of period $t$, equal to the square bracket in (9). Aggregate end of period assets of this group are $S^{a}=\sum_{\alpha \in \mathbb{N}^{a}} S_{\alpha}^{a} N_{\alpha}^{a}$. Since a fraction $1-\gamma^{a}$ dies, insurance firms collect assets $\left(1-\gamma^{a}\right) S^{a}$, but premiums must be paid to those who survive, adding up to $\pi^{a} \gamma^{a} S^{a}$. The insurance sector breaks even with a premium $\pi^{a}=\left(1-\gamma^{a}\right) / \gamma^{a}$ or $1+\pi^{a}=1 / \gamma^{a}$. If such insurance is available, an agent's assets next period are $A_{\alpha, t+1}^{a}=R_{t+1}\left(1+\pi_{t}^{a}\right) S_{\alpha, t}^{a}$ if she survives, or $\gamma^{A} A_{\alpha, t+1}^{A}=R_{t+1} S_{\alpha, t}^{A}$ as in (9).

Preferences are represented by the CES non-expected utility theory proposed by Farmer (1990) and Weil (1990) restricting individuals to being risk neutral with respect to variations in income but allowing for an arbitrary intertemporal 
elasticity of substitution. Let $\beta$ be a subjective discount factor reflecting the pure rate of time preference, and $\sigma$ the intertemporal elasticity of substitution. Agents maximise expected welfare over the remaining life-time. The recursive formulation of intertemporally separable preferences yields the Bellmann equation

$$
V\left(A_{\alpha, t}^{A}\right)=\max _{C_{\alpha, t}^{A}}\left[\left(C_{\alpha, t}^{A}\right)^{\rho}+\gamma^{A} \beta \cdot\left(V_{\alpha, t+1}^{A}\right)^{\rho}\right]^{1 / \rho}, \sigma \equiv 1 /(1-\rho) .
$$

As always in intertemporal models, we derive the familiar Euler equation of consumption growth. A higher interest tilts the consumption profile towards the future, relative to a given life-cycle income profile, and thus implies higher savings. The sensitivity with respect to interest depends on the intertemporal elasticity of substitution. One can now obtain a closed form solution for consumption and indirect utility. At any date, agents consume a fraction of their financial and human wealth where the marginal propensity to consume out of total wealth reflects present and future interest rates. Human wealth is the present value of expected pension benefits of retirees as stated in (8).

\section{Proposition 2:}

(a) The consumption function is

$$
C_{\alpha, t}^{A}=\left(1 / \Delta_{t}^{A}\right) \cdot\left(A_{\alpha, t}^{A}+H_{\alpha, t}^{A}\right) .
$$

The inverse of the marginal propensity to consume, $\Delta_{t}^{A}$, and human wealth equal to the present value of pension benefits, $H_{\alpha, t}^{A}$, are given by

$$
\Delta_{t}^{A}=1+\beta^{\sigma} R_{t+1}^{\sigma-1} \cdot \gamma^{A} \Delta_{t+1}^{A}, \quad H_{\alpha, t}^{A}=y_{t}^{A}+\gamma^{A} H_{\alpha, t+1}^{A} / R_{t+1} .
$$

(b) Indirect utility over remaining lifetime is

$$
V_{\alpha, t}^{A}=\left(\Delta_{t}^{A}\right)^{1 / \rho} C_{\alpha, t}^{A}=\left(\Delta_{t}^{A}\right)^{1 /(\sigma-1)} \cdot\left(A_{\alpha, t}^{A}+H_{\alpha, t}^{A}\right) .
$$

Proof: See Grafenhofer et al. (2006).

One may verify that the solution satisfies the intertemporal budget constraint that is obtained by solving forward the periodic budget in (9). The economics of intertemporal choice in the last age group is well known from the standard perpetual youth model. 


\subsection{Other age groups}

The key difference to the last age group is that members of groups $a<A$, be it active workers or retired persons, are subject to the risk of ageing while the last group is not. If hit by an ageing shock, the agent will inherit a different vector of life-cycle characteristics $\left(\theta^{a+1}, \gamma^{a+1}, \omega^{a+1}\right)$. The mortality rate increases, labour productivity changes, or work income is replaced by a pension when switching into retirement. Hence, a person's expected utility next period, conditional on surviving, is

$$
\bar{V}_{\alpha, t+1}^{a} \equiv \omega^{a} V_{\alpha, t+1}^{a}+\left(1-\omega^{a}\right) V_{\alpha^{\prime}, t+1}^{a+1} .
$$

With probability $\omega^{a}$, the agent will not age and will expect welfare $V_{\alpha, t+1}^{a}$ next period. With probability $1-\omega^{a}$, she will age, switch to the next higher age group and expect welfare $V_{\alpha^{\prime}, t+1}^{a+1}$. In this event, the agent's biography must be updated as in (2) with an extra entry $t+1$. The Bellmann equation, referring to the optimisation problem of an agent belonging to group $a<A$, becomes

$$
V\left(A_{\alpha, t}^{a}\right)=\max _{C_{\alpha, t}^{a}}\left[\left(C_{\alpha, t}^{a}\right)^{\rho}+\gamma^{a} \beta \cdot\left(\bar{V}_{\alpha, t+1}^{a}\right)^{\rho}\right]^{1 / \rho} .
$$

It is assumed, as in (9), that an actuarially fair, group-specific insurance scheme is also available to younger age groups. Hence, maximisation is subject to asset accumulation

$$
\gamma^{a} A_{\alpha, t+1}^{a}=R_{t+1}\left[A_{\alpha, t}^{a}+y_{t}^{a}-C_{\alpha, t}^{a}\right], \quad A_{\alpha, t+1}^{a}=A_{\alpha^{\prime}, t+1}^{a+1} .
$$

The value of assets is measured at the end of the period and, together with new savings $y-C$, earns an interest $r_{t+1}$ until the end of the next period. Note that a person inherits the same asset wealth in period $t+1$ from savings in period $t$ irrespective of whether he ages or not.

We derive a modified Euler equation of consumption growth. It states that desired consumption growth is a function of the expected interest rate relative to the subjective discount rate implicit in $\beta$. The interpretation is similar to that for the old age group. A higher interest tilts the consumption profile towards the future, relative to the life-cycle income profile $y^{a}$, and thus implies higher savings. A key difference to the last group is the risk of ageing, giving rise to a marginal rate of intertemporal substitution $(M R S)$ between two consecutive age states. Economic ageing thus introduces a magnification $\Omega^{a}=\omega^{a}\left(1+M R S^{a}\right)$ of the interest factor when discounting forward-looking variables. The following closed form solution for consumption and welfare is obtained. 


\section{Proposition 3:}

Optimal consumption policy $C_{\alpha, t}^{a}$ and indirect utility $V_{\alpha, t}^{a}$ are

(i) $C_{\alpha, t}^{a}=\left(1 / \Delta_{t}^{a}\right) \cdot\left(A_{\alpha, t}^{a}+H_{\alpha, t}^{a}\right), \quad \sigma=1 /(1-\rho)$,

(ii) $V_{\alpha, t}^{a}=\left(\Delta_{t}^{a}\right)^{1 / \rho} C_{\alpha, t}^{a}$,

(iii) $\Delta_{t}^{a}=1+\gamma^{a} \beta^{\sigma}\left(\Omega_{t+1}^{a} R_{t+1}\right)^{\sigma-1} \Delta_{t+1}^{a}$,

(iv) $\Omega_{t+1}^{a}=\omega^{a}+\left(1-\omega^{a}\right)\left(\Lambda_{t+1}^{a}\right)^{1-\rho}, \quad \Lambda_{t+1}^{a}=\left(\Delta_{t+1}^{a+1} / \Delta_{t+1}^{a}\right)^{1 / \rho}$,

(v) $H_{\alpha, t}^{a}=y_{t}^{a}+\gamma^{a} \bar{H}_{\alpha, t+1}^{a} /\left(\Omega_{t+1}^{a} R_{t+1}\right)$,

(vi) $\bar{H}_{\alpha, t+1}^{a}=\omega^{a} H_{\alpha, t+1}^{a}+\left(1-\omega^{a}\right)\left(\Lambda_{t+1}^{a}\right)^{1-\rho} H_{\alpha^{\prime}, t+1}^{a+1}$.

The marginal propensity to consume is $1 / \Delta$ and $H$ denotes human capital equal to the present value of future wages and pension benefits.

Proof: See Grafenhofer et al. (2006).

Note that an agent cannot age any further, $\omega^{A}=1$, if she is in the last age state. In that case, $\Omega^{A}=1$, which yields the solution for the last age group as in proposition 2. Second, if all age classes face the same survival probability $\gamma^{a}=\gamma$ and thereby differ only in their earnings, then the marginal propensity to consume is invariant across age classes. This is most easily seen in the case of a unit elasticity $\sigma=1$ which yields $1 / \Delta=1-\beta \gamma$ by (17.iii), but is also true more generally. If $\Delta^{a+1}=\Delta^{a}$, then both $\Lambda^{a}$ and $\Omega^{a}$ are equal to one, implying $\Delta_{t}^{a}=1+\gamma \beta^{\sigma}\left(R_{t+1}\right)^{\sigma-1} \Delta_{t+1}^{a}$. Hence, $\Delta^{a}$ must indeed be the same for all groups. Age classes then differ only in terms of human wealth and consumption levels but all choose the same intertemporal consumption structure. This shows that the change in the marginal propensity to consume from one age class to the next exclusively reflects a change in the mortality rate.

Consider the most realistic case that the mortality rate increases between any two consecutive groups. Again, the Cobb Douglas case shows most transparently that the marginal propensity to consume $1 / \Delta^{a}=1-\gamma^{a} \beta$ rises with a lower survival rate $\gamma^{a}$. Given that the ratio $\Delta^{a+1} / \Delta^{a}$ falls below unity, and that $\rho<0$ for an intertemporal substitution elasticity $\sigma<1$, the factor $\Lambda^{a}$ exceeds one and thereby raises $\Omega^{a}$ above one as well. Agents start to discount the future more heavily, at an effective rate $\Omega^{a} R$, as the end of life becomes a more probable event. With a higher probability of extinction, agents are less inclined to wait and thus consume a larger fraction of resources immediately. The marginal propensity to consume thus increases as the last age state is approached, which is a key feature of the life-cycle model in the tradition of Auerbach and Kotlikoff (1987). 
In fact, our model becomes identical to the Auerbach Kotlikoff model when the number of economic states of age approaches the number of life-cycle periods (set $\omega^{a}=0$, see again Grafenhofer et al. 2006, for a proof).

In the EA model, all agents in a given state of economic age move to the next state with the same transition rate $\omega^{a}$, and face the same survival rate $\gamma^{a}$. As in the perpetual youth model in line with Blanchard (1985) and Yaari (1965), a critical assumption necessary for analytical aggregation below is that these rates are independent of how long agents have already spent in state $a$. This creates a large heterogeneity of economic ageing patterns with some agents moving very fast to retirement and others remaining in a productive young state for many periods. It might be considered a weakness that the EA model can produce quite unrealistic individual ageing trajectories. However, the applications are not concerned with individual trajectories but with the aggregate behaviour of age groups. In the aggregate, an age group replicates the average of the cohorts which define the characteristics of this group as is emphasised in the calibration principles applied in Section 4 below. Another limitation might be that transition probabilities are not shaped by individual behaviour and that the demographic subsystem is independent of economic decisions. While the analysis of the demographic scenarios in Section 5 rests on the assumption of exogenous fertility shocks, it should be possible to endogenise fertility, for example, along the lines of Weil (2006). A final restriction of the model is that all characteristics of economic age such as wage and mortality rate change at the same time. One might also question whether individuals sharing the same wage in a given age group would also share the same mortality rate. However, one might again argue that the value of the model for macroeconomic analysis is in describing average life-cycle patterns resulting from the aggregate behaviour of age groups rather than tracing out the full heterogeneity of individual life-cycle patterns.

\subsection{Aggregation}

The simplicity and tractability of the simple perpetual youth with a constant mortality rate rests on the fact that it allows for analytical aggregation. The same applies to the EA (economic ageing) model. The advantage of approximating actual demographic and life-cycle properties with a low dimensional system is possible only if age groups can be aggregated analytically. In Section 2, we argued that agents are uniquely identified by their biography $\alpha$ which also includes the date of birth as a first entry. In age group $a$, one records at date $t$ a mass of agents $N_{\alpha, t}^{a}$ with the same life-cycle history. These agents are 
economically identical and all consume the same quantity $C_{\alpha, t}^{a}$. Aggregate consumption of age group $a$ is obtained by adding all possible biographies. Economy-wide consumption is then the sum of age-group specific aggregates,

$$
C_{t}^{a} \equiv \sum_{\alpha \in \mathrm{N}_{t}^{a}} C_{\alpha, t}^{a} N_{\alpha, t}^{a}, \quad C_{t} \equiv \sum_{a=1}^{A} C_{t}^{a} .
$$

The same principle applies to other static variables. When aggregating expressions that multiply with variables that are identical within an age group, or identical over the entire population, these constant terms drop out of the addition. For example, aggregating wage related income in (8) yields $\sum_{\alpha} y_{t}^{a} N_{\alpha, t}^{a}=y_{t}^{a} N_{t}^{a}$. Denoting labour supply in efficiency units by $L^{S}$ and the retirees by $N^{R}$, the result is

$$
Y_{t}^{a}=y_{t}^{a} N_{t}^{a}, \quad Y_{t}=\left(1-t^{W}\right) w_{t} L_{t}^{S}+p_{t} N_{t}^{R},
$$

where $L_{t}^{S} \equiv \sum_{a<a^{R}} \theta^{a} N_{t}^{a}$ and $N_{t}^{R} \equiv \sum_{a \geq a^{R}} N_{t}^{a}$.

Similarly, when aggregating the consumption function of age group $a$ stated in (11) and (17.i), we observe that the terms $\Delta_{t}^{a}, \Lambda_{t}^{a}$ and $\Omega_{t}^{a}$ are identical within each group. They implicitly depend on the common interest rate and demographic parameters that differ across age groups due to different mortality rates. Being forward looking, they are independent of history within each group. Hence, aggregate consumption is simply $C_{t}^{a}=\left(A_{t}^{a}+H_{t}^{a}\right) / \Delta_{t}^{a}$.

The aggregation of human capital is particularly simple in this basic model since wage-related income and thus human capital per capita is the same for all persons within each group. This is most easily seen by solving forward (12) which yields the same present value of future income, discounted at a common rate, for all retirees. Writing the per capita value as $H_{\alpha, t}^{A}=h_{t}^{A}$, aggregate human capital is simply $H_{t}^{A}=h_{t}^{A} N_{t}^{A}$. The same holds for all earlier age groups as is obvious from (17.v). Hence,

$$
H_{t}^{a}=h_{t}^{a} N_{t}^{a}, \quad h_{t}^{a} \equiv H_{\alpha, t}^{a}, \quad h_{t}^{a}=y_{t}^{a}+\gamma^{a} \cdot \frac{\omega^{a} h_{t+1}^{a}+\left(1-\omega^{a}\right)\left(\Lambda_{t+1}^{a}\right)^{1-\rho} h_{t+1}^{a+1}}{\Omega_{t+1}^{a} R_{t+1}} .
$$

The law of motion for human capital per capita is repeated from (17.v-vi). The law of motion for the oldest age group follows on account of the restriction $\omega^{A}=1$, implying $\Omega^{A}=1$, and corresponds to the equation in (12).

Aggregate asset accumulation of age group $a$ is

$$
A_{t+1}^{a}=R_{t+1}\left[\omega^{a} S_{t}^{a}+\left(1-\omega^{a-1}\right) S_{t}^{a-1}\right], \quad A_{t+1}^{1}=R_{t+1} \omega^{1} S_{t}^{1},
$$

where $S_{t}^{a}=A_{t}^{a}+Y_{t}^{a}-C_{t}^{a}$ denotes end-of-period assets. The proof is in Grafenhofer et al. (2006). Note that newborns entering the first age group are 
devoid of any assets since by definition the unborn members of age group 0 cannot save. Finally, total asset accumulation amounts to

$$
A_{t+1}=R_{t+1}\left[A_{t}+Y_{t}-C_{t}\right], \quad A_{t}=\sum_{a} A_{t}^{a},
$$

where $Y$ is aggregate wage related income.

\subsection{General equilibrium}

Production of output $Q_{t}$ is subject to a linear homogeneous, quasiconcave technology $F$ using capital $K_{t}$ and efficiency units of labour $L_{t}$ as inputs. For realistic dynamics of investment in a small open economy, investment costs $I^{C}$ are assumed to increase progressively with the rate of gross investment, reflecting installation costs of capital. The capital installation technology is again assumed to be linearly homogeneous, leading to investment costs $I^{C}=\phi(I, K)$, where $I$ is the amount of gross investment, and $\phi_{I}>0, \phi_{I I}>0$, and $\phi_{K}<0$. As a normalisation, we may specify $\delta=\phi(\delta, 1)$, implying that $I^{C}=I$ in a steady state. Dividends $\chi_{t}$ are

$$
\chi_{t}=Q_{t}-w_{t} L_{t}-I_{t}^{C}, \quad Q_{t}=F\left(K_{t}, L_{t}\right), \quad I^{C}=\phi(I, K) .
$$

Defining the end of period, cum dividend value of capital by $V^{K}$, optimal investment and employment policies follow from

$$
V^{K}\left(K_{t}\right)=\max _{I_{t}, L_{t}} \chi_{t}+V^{K}\left(K_{t+1}\right) / R_{t+1} \quad \text { s.t. } K_{t+1}=I_{t}+(1-\delta) K_{t} .
$$

Discounting with the households' interest factor $R_{t+1}$ assures that the noarbitrage condition of investors is satisfied, i.e., the return on dividend generating capital must equal the market rate of interest available on alternative assets. Denoting the shadow price of capital by $\lambda_{t}^{K} \equiv \partial V_{t} / \partial K_{t}$, the optimality and envelope conditions are

$$
\phi_{I}=\lambda_{t+1}^{K} / R_{t+1}, w_{t}=F_{L}, \lambda_{t}^{K}=F_{K}-\phi_{K}+(1-\delta) \lambda_{t+1}^{K} / R_{t+1} .
$$

It has been well known since Hayashi (1982) that the marginal and average shadow prices of capital are identical, $V_{t}^{K} \equiv \lambda_{t+1}^{K} K_{t}$. Finally, it should be noted that in a steady state, $I=\delta K$. Due to our normalisation of the adjustment cost function $\phi$, we have $\phi_{I}=1$ and $\phi_{K}=0$ in a steady state, which yields the familiar condition $F_{K}=r+\delta$.

The model is closed by imposing the consolidated government budget constraint. Wage taxes must finance public consumption $G$, which is kept constant per capita of the total population, and PAYG pension spending where $L^{S}$ and $N^{R}$ are given in (19), 


$$
t^{W} w_{t} L_{t}^{S}=p_{t} N_{t}^{R}+G_{t}, \quad G_{t}=g \cdot N_{t} .
$$

In equilibrium, demand for efficiency units of labour must correspond to household sector labour supply, scaled by worker productivity. In addition, accumulated private financial wealth must absorb the value of domestically issued equity, $V_{t+1}$, and foreign bonds $D_{t+1}$,

$$
L_{t}=L_{t}^{S}, \quad A_{t+1}=V_{t+1}^{K}+D_{t+1} .
$$

When assets are perfectly substitutable, they must earn an identical rate of return equal to the market interest $r_{t+1}$. Given optimal household and firm behaviour, and with all budget constraints fulfilled, Walras' Law implies the current account

$$
D_{t+1}=R_{t+1}\left[D_{t}+Q_{t}-I_{t}^{C}-G_{t}-C_{t}\right],
$$

where the stock of foreign net assets $D_{t}$ is measured at the end of the period.

\section{Calibration to life-cycle data}

In standard OLG models with an annual ageing process, the population is divided into different vintages or cohorts identified by the year of birth. In these "cohort" models, individuals age every single period. There are thus as many age groups as cohorts, 55 as in the original Auerbach and Kotlikoff (1987) model. The purpose of this section is to show how the EA model incorporates life-cycle features even if only a few age groups are distinguished. The degree of approximation depends on the number of age groups and, therefore, on the number of state variables. By drastically reducing the state space in this way, one can greatly simplify the quantitative, empirical analysis of life-cycle economies. In the end, one must decide on a trade-off between life-cycle accuracy and the dimensions of the numerical model. In all cases, however, the EA model allows for a period length of one year, independent of the number of age groups chosen, which is important for short-run and transitional dynamics.

\subsection{Demography and wage profiles}

The empirical implementation of the EA model on real population data rests on the fact that it contains the annual cohort model as a special case. For simplicity, we consider a demographic stationary state and thus ignore time indices. Setting $\omega^{a}=0$ in equation (4) implies that an ageing event occurs with probability one 
in each period, leading to $\tilde{N}^{t}=\tilde{\gamma}^{t-1} \widetilde{N}^{t-1}$. The concept of an age group thus becomes identical with a cohort or vintage where age $t$ is measured by time since birth. The tilde indicates the decomposition in annual cohorts or population vintages $\tilde{N}^{t}$. We now take the age-dependent survival rates $\tilde{\gamma}^{t}$ from official mortality tables and construct the cohort composition of the population in a demographic steady state. Recursively applying $\widetilde{N}^{t}=\widetilde{\gamma}^{t-1} \widetilde{N}^{t-1}$ yields the size of cohort $t$ relative to the size of a new cohort. Summing up over all cohorts fixes the size of the new cohort compared to total population size $N$,

$$
\tilde{N}^{t}=\tilde{N}^{1} \prod_{s=1}^{t-1} \tilde{\gamma}^{s}, \quad \tilde{N}^{1}=N / \sum_{t=1}^{T} \prod_{s=1}^{t-1} \tilde{\gamma}^{s} .
$$

Taking a total length of life of $T$ years, and based on actual survival rates, we have thus found the stationary breakdown of the population into a total of $T$ cohorts or vintages. Alternatively, the total population may be broken down into broader age groups $N^{a}$ with each one containing several vintages,

$$
\sum_{t=1}^{T} \tilde{N}^{t}=N=\sum_{a=1}^{A} N^{a} .
$$

For the sake of concreteness, let us assume that total lifetime consists of $T=70$ periods as in Table 1, which considers the active population starting at age 20 and living until age 90 . The total population is divided into a cross-section of eight age groups. The first six are equally spaced and contain 10 cohorts each, the very old are subdivided into two smaller groups with five cohorts each. The first group contains vintages $N^{1}=\sum_{t=20}^{29} \widetilde{N}^{t}$. Line 3 of Table 1 lists the population shares that obtain from actual, non-stationary population data. Line 4 reports the shares that result from a stationary population distribution.

Table 1:

\begin{tabular}{|c|c|c|c|c|c|c|c|c|}
\hline 1. Age groups & 1 & 2 & 3 & 4 & 5 & 6 & 7 & 8 \\
\hline 2. Cohorts & $20-29$ & $30-39$ & $40-49$ & $50-59$ & $60-69$ & $70-79$ & $80-84$ & $85-89$ \\
\hline 3. Data $N^{a} / N$ & 0.168 & 0.222 & 0.192 & 0.168 & 0.120 & 0.089 & 0.025 & 0.016 \\
\hline 4. Model Nª $/ N$ & 0.179 & 0.177 & 0.175 & 0.168 & 0.148 & 0.107 & 0.031 & 0.016 \\
\hline 5. Labour prod. $\theta^{\mathrm{a}}$ & 1.000 & 1.362 & 1.561 & 1.582 & 1.295 & 0.000 & 0.000 & 0.000 \\
\hline 6. Prob. 1- $\gamma^{a}$ & 0.001 & 0.001 & 0.004 & 0.012 & 0.028 & 0.042 & 0.096 & 0.200 \\
\hline 7. Prob. 1- $\omega^{a}$ & 0.099 & 0.099 & 0.096 & 0.089 & 0.074 & 0.061 & 0.115 & 0.000 \\
\hline 8. Factor $\Omega^{\mathrm{a}}$ & 1.017 & 1.024 & 1.032 & 1.038 & 1.040 & 1.062 & 1.080 & 1.000 \\
\hline 9. Propens. $1 / \Delta^{\mathrm{a}}$ & 0.046 & 0.050 & 0.057 & 0.068 & 0.084 & 0.109 & 0.167 & 0.228 \\
\hline
\end{tabular}

Demographic and life-cycle parameters

Notes: $\theta^{\mathrm{a}}$ life-cycle labour productivity determines wage, $\mathrm{w}^{\mathrm{a}}=\mathrm{w} \theta^{\mathrm{a}}, 1-\gamma^{\mathrm{a}}$ probability of dying, 1- $\omega^{\mathrm{a}}$ probability of ageing, $\Omega^{\mathrm{a}}$ magnification interest factor reflecting increase in mortality, $1 / \Delta^{\mathrm{a}}$ marginal propensity to consume. Source: BFS (2004) and own calculations. 
Calibration must assure that the average behaviour of age groups in the EA model (line 1 in Table 1) replicates the average behaviour of the cohorts that define these age groups (line 2). Line 2 defines an aggregation key which collects cohorts in corresponding age groups. This aggregation key corresponds to a particular life-cycle biography $\alpha=(20,30,40, \ldots, 80,85)$ where $\alpha_{1}=20$ is the date of birth, i.e., the true age when an agent starts economic life. The first requirement is that that the total mass of the age groups is identical to the mass of cohorts in line 4 which define these groups. Therefore, the parameters $\omega^{a}$ and $\gamma^{a}$ of the EA model must be set so that its demographic steady state fulfills (4-5),

$$
\left(1-\gamma^{a} \omega^{a}\right) \cdot N^{a}=\left(\gamma^{a-1}-\gamma^{a-1} \omega^{a-1}\right) \cdot N^{a-1},\left(1-\gamma^{1} \omega^{1}\right) \cdot N^{1}=n .
$$

At any date in time, the instantaneous probability of staying in group $a$ is $\omega^{a} \gamma^{a}$, which implies an expected duration of $1 /\left(1-\omega^{a} \gamma^{a}\right)$ in group $a$. To pin down the remaining degrees of freedom, we impose as a second restriction that the expected number of years spent in group $a$ is equal to the number of lifecycle cohorts that are collected in this group. Taking the aggregation key $\alpha=(20,30,40, \ldots, 80,85)$, we have

$$
\alpha_{a+1}-\alpha_{a}=1 /\left(1-\omega^{a} \gamma^{a}\right) \text {. }
$$

Knowing $N^{a}$ from aggregated population data and $\omega^{a} \gamma^{a}$ from age group duration as implied by the chosen aggregation key, one can pin down demographic parameters by the following recursive procedure. Knowing $\gamma^{a}$ and $\omega^{a}$, equations (31-32) are solved simultaneously for $\gamma^{a-1}$ and $\omega^{a-1}$. We start the recursion with the last group where $\gamma^{A}$ follows directly from (31) on account of the restriction $\omega^{A}=1$. Lines 6 and 7 of Table 1 list the resulting values of the exit probabilities. Figure 1 illustrates how these values approximate the true mortality rates from demographic data. The step function reflects the fact that mortality rates are assumed to be identical for all agents within an age class. 
Figure 1:

Actual and calibrated mortality rates

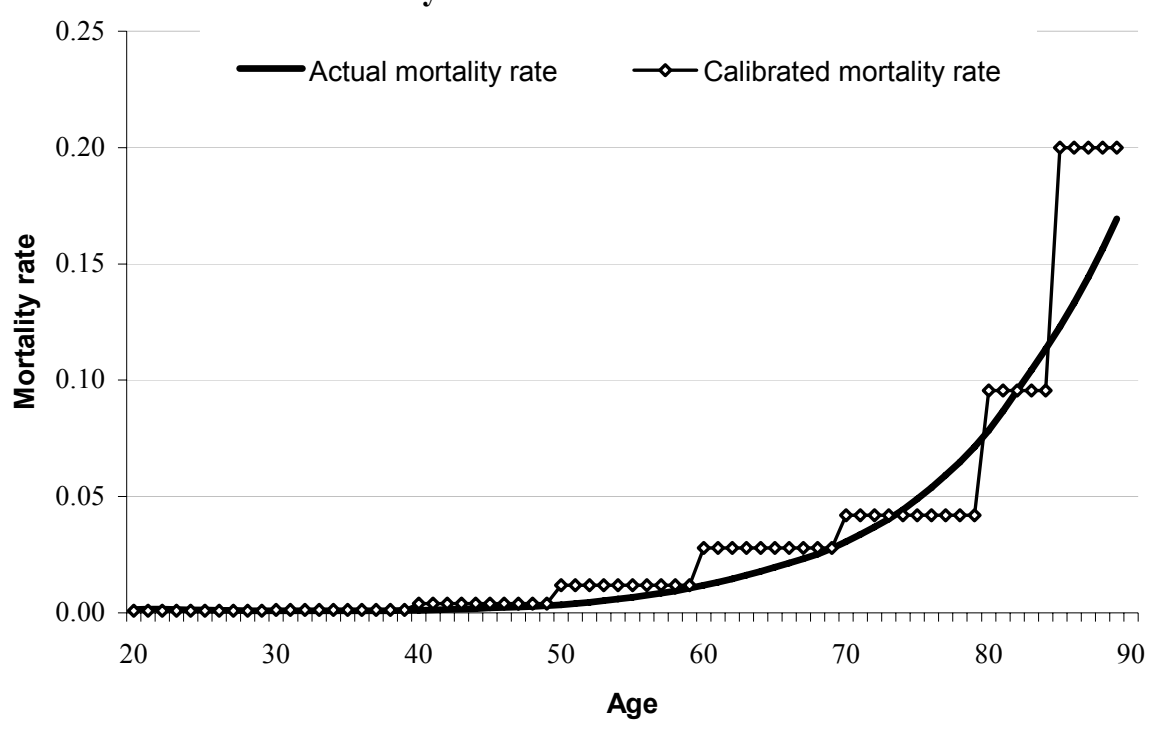

Source: BFS (2004).

As a next step, we use actual wage data to find the life-cycle productivity parameters $\theta^{a}$. For any given wage per efficiency unit of labour one obtains wages $w^{a}=w \theta^{a}$. The life-cycle profiles of annual wages $\widetilde{w}^{t}$ are readily available from cohort data. We now require that the uniform, group-specific wage $w^{a}$ is equal to the average of cohort-specific wages $\widetilde{w}^{t}$, taking the shares $\widetilde{N}^{t} / N^{a}$ of the cohorts in that age group as weights:

$$
w^{a}=\sum_{t=\alpha_{a}}^{\alpha_{a+1}-1} \widetilde{w}^{t} \cdot \widetilde{N}^{t} / N^{a} .
$$

Figure 2 illustrates how (33) approximates the empirical wage profile. The solid, ragged line shows actual wage data for each cohort in Switzerland in 2000. The solid step function with 10 year intervals corresponds to line 5 in Table 1 . Note that the wage of group 5 is an average of a relatively high wage prior to and a zero wage after retirement when people are in their late sixties. The dashed line with 20 year intervals represents only 4 age groups with the first three comprising 20 cohorts and the last one 10 cohorts. Obviously, the approximation is crude for periods early and late in the life-cycle while it makes not much difference for agents in their mid-life. Finally, the dashed line with 5 year intervals comes much closer to the true wage profile by taking averages over fewer cohorts. The gains in empirical approximation are highest for the youngest cohorts facing a steep wage profile, and for the cohorts close to retirement. 
Figure 2:

Life-cycle wages

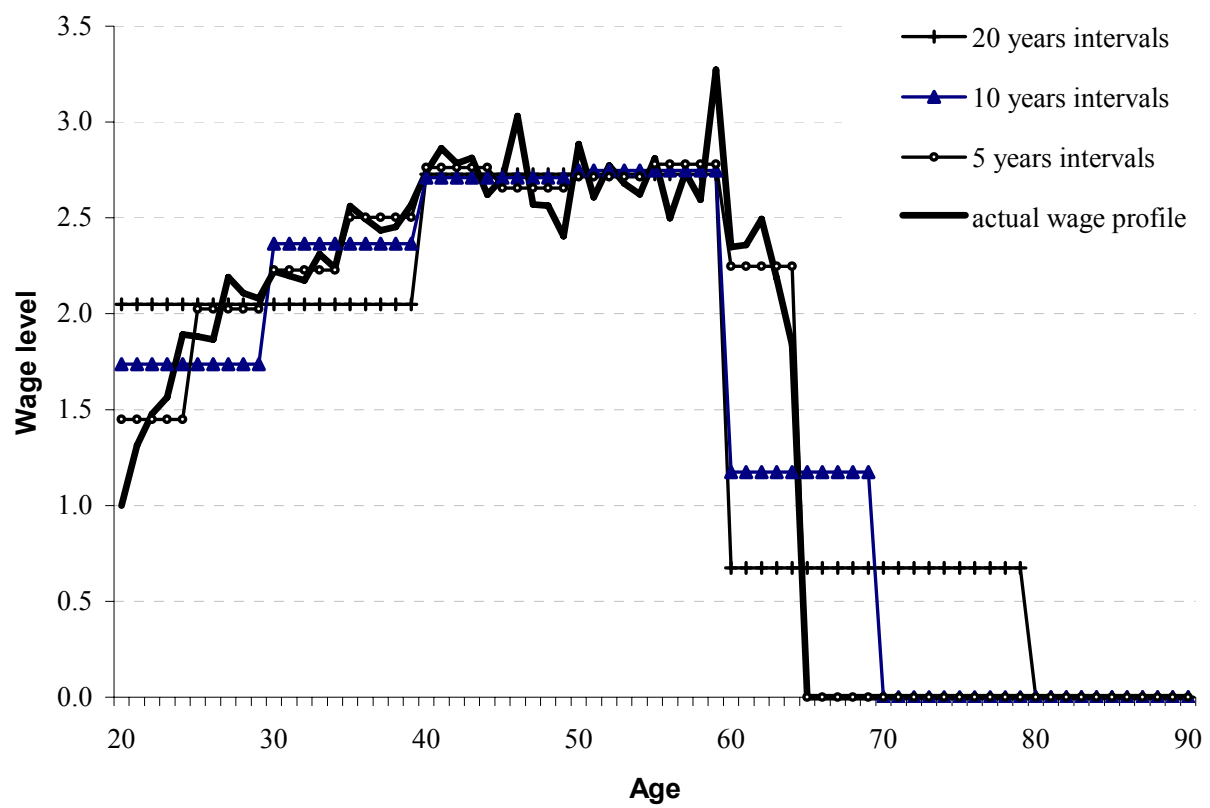

Source: BFS (2004).

Line 8 in Table 1 lists the factor $\Omega^{a}$ which reflects the agents' response to increasing finiteness of life over the life-cycle. The discussion of proposition 3 showed that the marginal propensity to consume rises as the end of life, in the sense of a shorter remaining expected lifetime, approaches. Agents are less inclined to postpone consumption when mortality is high and when the fruits of savings might thus not be enjoyed. Consequently, agents value current consumption in state $a+1$ relatively more than in state $a$ where mortality is still low. The marginal rate of substitution, measuring the amount of income to be given up in state $a$ for an extra Euro of consumption and income in state $a+1$, is thus large when mortality in state $a+1$ is high compared to state $a$. This higher value of the marginal rate of substitution works like a magnification $\Omega^{a}>1$ of the interest factor. Intuitively, agents start to discount the future more heavily, at an effective rate $\Omega^{a} R$, as the end of life becomes a more probable event. Inspecting the marginal propensity to consume in a steady state, $1 / \Delta^{a}=1-\gamma^{a} \beta^{\sigma}\left(\Omega^{a} R\right)^{\sigma-1}$, one finds that the increasing finiteness of life raises it for two reasons. First, the declining survival probability $\gamma^{a}$ directly raises the consumption propensity. Second, this effect is magnified by the presence of $\Omega^{a}>1$. If $1 / \Delta^{a}$ rises for older groups, then $\Delta^{a+1} / \Delta^{a}<1$, implying $\Lambda^{a}>1$ and 
$\Omega^{a}>1$. Lines 8 and 9 of Table 1 clearly illustrate these life-cycle features. As is typical for OLG models, consumption propensities increase substantially as agents move to higher age groups, reflecting a shorter remaining expected lifetime.

\subsection{Economic parameters}

Table 2 sets out key parameters that characterise preferences and technology. These are commonly used values as in Altig et al. (2001) and Blundell et al. (2003), for example, or in the real business cycle literature as in Baxter and King (1993) or King, Plosser, and Rebelo (1988). To keep the discussion short, we refer to these papers for a discussion and review of the econometric literature. The subjective discount rate is calibrated to replicate savings. The replacement rate gives the size of the pension compared to the last net wage income. While in many European countries with generous PAYG old age insurance systems, a replacement rate of around $70 \%$ would be typical, the PAYG system plays a much smaller role in Switzerland where it is supplemented by a substantial assetbacked, funded component. The replacement rate of the PAYG part is thus only $38 \%$. Tax revenue is used to finance government consumption and pension payments and requires a wage tax rate of $30 \%$.

Table 2:

Taste and technology parameters

\begin{tabular}{ll}
\hline Real interest rate $r$ & 0.050 \\
Depreciation rate $\delta$ & 0.100 \\
Output elasticity of capital $\alpha$ & 0.350 \\
Subjective discount factor $\beta$ & 0.983 \\
Intertemporal elasticity of substitution $\sigma$ & 0.400 \\
Wage elasticity of labour supply $\varepsilon^{L}$ & 0.400 \\
Semi-elasticity of retirement $\varepsilon^{R}$ & 1.000 \\
Proportional wage tax rate $t^{W}$ & 0.308 \\
Pension replacement rate $\zeta$ & 0.381 \\
\hline
\end{tabular}

Notes: The labour supply elasticity is $\varepsilon^{\mathrm{L}} \equiv \varphi^{\prime} /\left(1 \varphi^{\prime \prime}\right)$, the pension replacement rate $\zeta=\mathrm{p} /\left[\left(1-\mathrm{t}^{\mathrm{W}}\right) \mathrm{w} \theta^{\alpha^{\mathrm{R}}-1}\right]$, and the production function $\mathrm{Q}=\mathrm{XK}^{\alpha}(\mathrm{ZL})^{1-\alpha}$.

To capture the labour market effects of demographic change in more detail, we have extended the basic EA model in the Appendix to include endogenous labour supply. These extensions refer to the intensive (hours worked) and extensive margins (retirement, or participation decision of workers near 
retirement) of labour supply. Essentially, workers supply more hours if the net of tax wage increases. The participation/retirement decision of workers in age group 5 , corresponding to people in their sixties, reflects the difference between work and retirement income. The larger the difference, the more agents find it worthwhile to postpone retirement so that the participation rate in this group increases. The retirement elasticity is taken from empirical studies. Börsch-Supan (2000) estimates that a decrease in benefits by $12 \%$ would reduce the retirement probability of 60 -year-olds from $39.3 \%$ to $28.1 \%$. The corresponding increase in the participation rate amounts to a semi-elasticity of retirement equal to one.

\section{Demographic change}

\subsection{Baby boom}

To demonstrate the usefulness and flexibility of the EA model, we choose two key scenarios of demographic change where the standard perpetual youth model is most restrictive. The first scenario mimics the consequences of a temporary baby boom. We raise the inflow of newborns by 30 per cent over a 20 year period, and then set it back to the original value in the initial demographic steady state. A demographic shock of this scale is not without precedent. According to Russell (1982), the number of births in the US amounted to 76 million over the period 1946-64, which is 17 million or $28.9 \%$ more than over the 18 years preceding the baby boom. With no other disturbances, the economy will eventually return to the initial equilibrium over a prolonged adjustment period.

Figure 3 illustrates how the EA model captures the demographic impact of the temporary baby boom. The first age group, which collects all agents with the characteristics of people in their twenties, rapidly grows larger. It attains its maximum size in period 2020 where it exceeds its initial size by $26 \%$. Some of these newcomers move rather soon to the next economic age group. With some delay, age group two with the characteristics of people in their thirties starts to grow as well. This group attains maximum size somewhat later in period 2023 when it is $19 \%$ larger than in the initial equilibrium. As is evident from Figure 3, higher age groups grow even more slowly and take much longer to reach maximum size, and the increase compared to the initial steady state becomes smaller. The total population peaks in period 20 when the baby boom ends. 
Figure 3:

Demographic impact of a baby boom

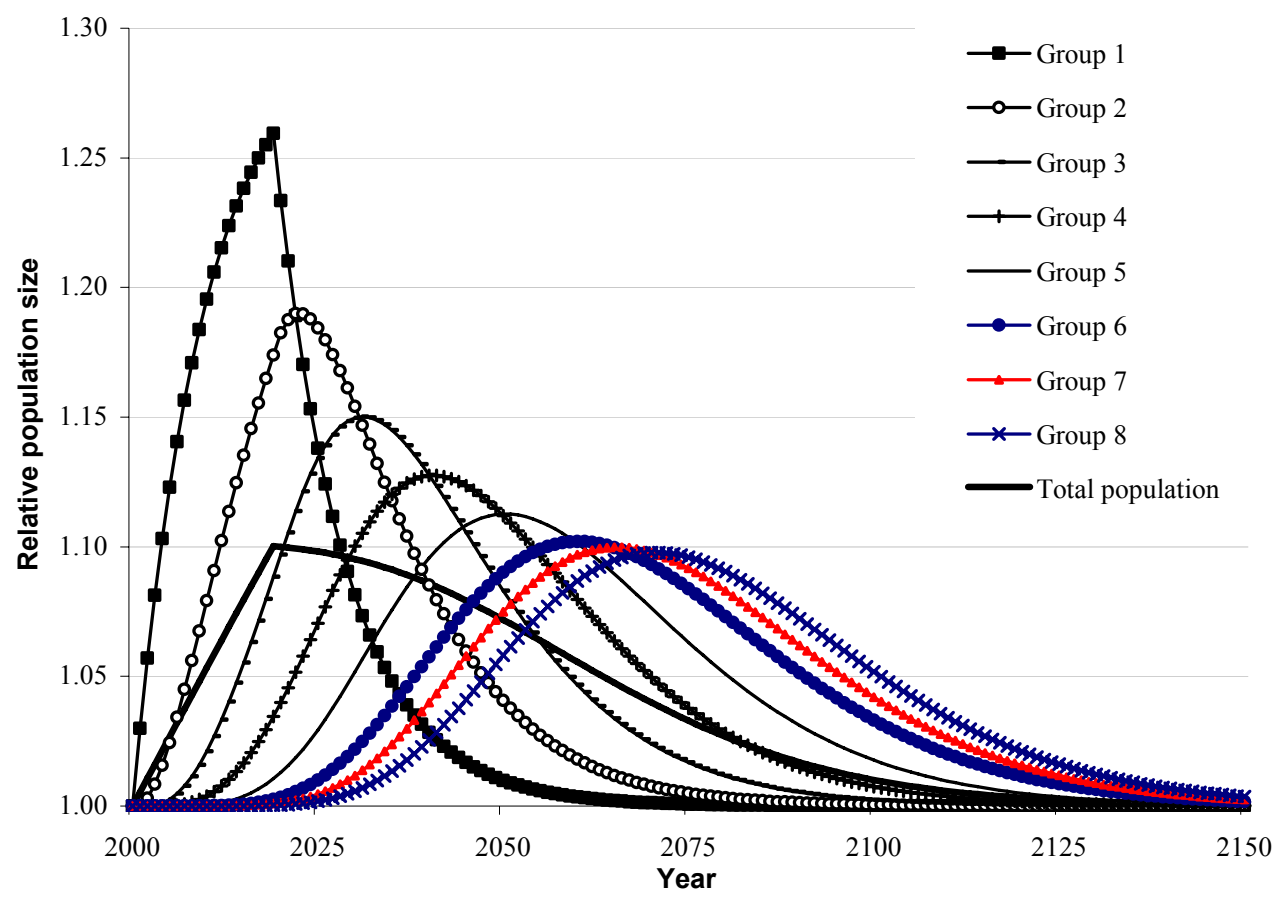

Figure 4 shows how a temporary baby boom might result in large swings in the net foreign asset position. In an open economy, net foreign assets $D=A-V^{K}$ as in (27) are equal to the stock of household sector financial wealth minus the value of the domestic capital stock (firm value), and thus reflect the imbalance between domestic savings and investment. Since the net foreign asset position is a predetermined variable, it starts out from zero. The instantaneous decline in domestic financial assets reflects a windfall loss in firm values $V^{K}$. Given a predetermined value of net foreign assets, this leads to an instantaneous decline of household sector assets in exactly the same amount, as Figure 4 illustrates. As the baby boom continues, aggregate labour supply grows over a prolonged period and is reversed again when the baby boom ends. Capital accumulation, and therefore the value of the capital stock as plotted in Figure 4, follow closely the same hump-shaped pattern. However, due to the slow demographic process, it takes much longer until the increased labour income actually translates into an increase in aggregate financial wealth $A$. Since the value of capital outpaces the accumulated savings of domestic households, the difference must be borrowed on world capital markets, leading to a prolonged period of current account deficits and increasing net foreign debt. After the baby 
boom ends and the birth rate is back to normal, the domestic capital stock declines again to follow the shrinking labour force. Aggregate assets continue to increase on account of the savings of the baby boomers which reverses the growth of net foreign assets. After slightly more than four decades, the net asset position turns positive and reaches a maximum after about two more decades. Thereafter, the economy monotonously returns to the initial stationary equilibrium.

\section{Figure 4:}

\section{Baby boom and net foreign assets}

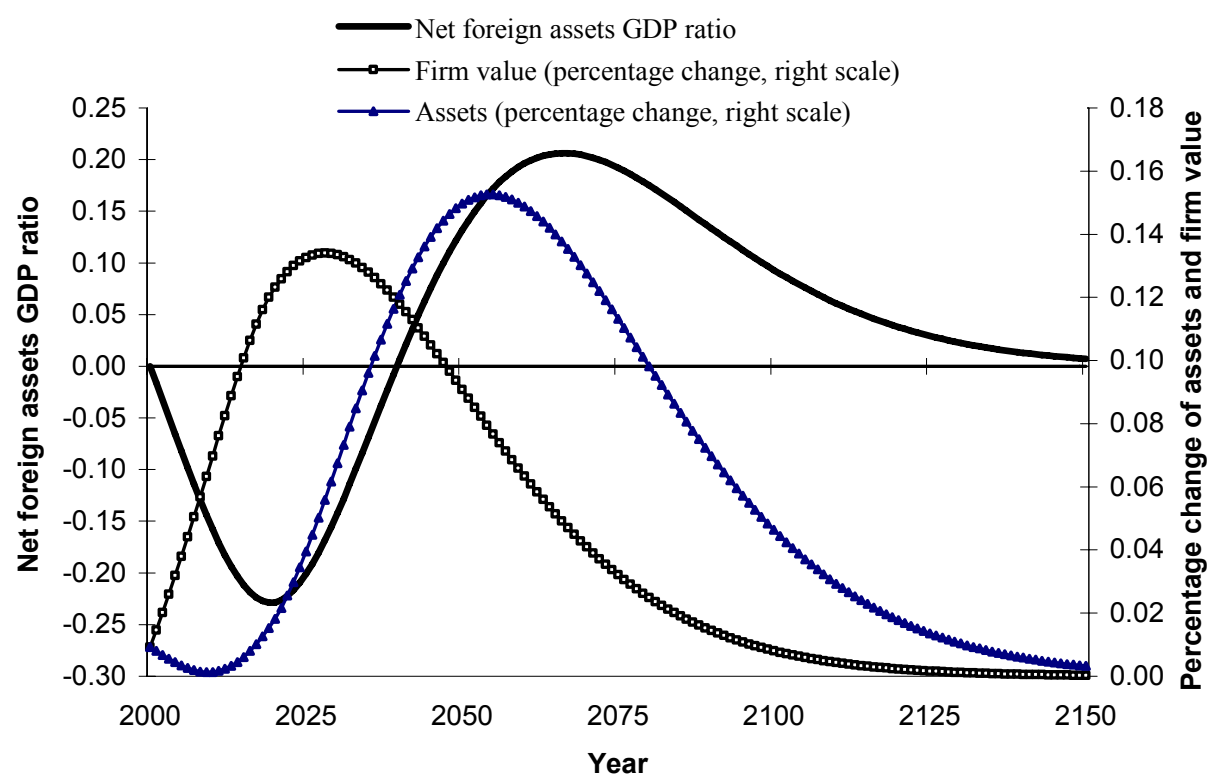

\subsection{Higher life expectancy}

The second scenario is an ageing scenario where people become older on average and potentially live longer. The two statements are not identical. The first one means that the mass of people in their 80 s becomes larger if more of the younger agents make it to their $80 \mathrm{~s}$. The second one means that the lifetime horizon becomes longer. To implement the scenario, we raise the survival rates of age groups 5 to 8 by the factors given in line 4 of Table 3 but keep the expected duration in each age group constant. If people in their seventies become less mortal, they have a higher chance of reaching the next age group of people in 
their eighties. ${ }^{5}$ Comparing columns 6 in Tables 1 and 3 shows that the mortality rate $1-\gamma^{a}$ of this group declines from .042 to .023 , which necessarily implies that a larger fraction of this group moves to the next one, instead of dying. The transition rate of ageing $1-\omega^{a}$ increases from .061 to .079 . Finally, since the last group becomes less mortal, $1-\gamma^{8}$ falling from .2 to .12 , expected duration in that group rises from 5 to $\left(1-\gamma^{8}\right)^{-1}=8.3$ years. The representative agent lives longer, 93.3 instead of 90 years. ${ }^{6}$

Table 3:

Ageing and life expectancy

\begin{tabular}{l|cccccccc}
\hline 1. Age group & 1 & 2 & 3 & 4 & 5 & 6 & 7 & 8 \\
\hline 2. Initial $\boldsymbol{N}^{\boldsymbol{a}}$ & 0.179 & 0.177 & 0.175 & 0.168 & 0.148 & 0.107 & 0.031 & 0.016 \\
3. New $\boldsymbol{N}^{\boldsymbol{a}}$ & 0.167 & 0.165 & 0.163 & 0.156 & 0.138 & 0.113 & 0.044 & 0.054 \\
4. Factor $\mathbf{x}^{\boldsymbol{a}}$ & 1.000 & 1.000 & 1.000 & 1.000 & 1.010 & 1.020 & 1.050 & 1.100 \\
5. Prob. $\mathbf{1}-\boldsymbol{\gamma}^{\boldsymbol{a}}$ & 0.001 & 0.001 & 0.004 & 0.012 & 0.018 & 0.023 & 0.050 & 0.120 \\
6. Prob. $\mathbf{1}-\boldsymbol{\omega}^{\boldsymbol{a}}$ & 0.099 & 0.099 & 0.096 & 0.089 & 0.083 & 0.079 & 0.158 & 0.000 \\
\hline
\end{tabular}

Notes: $1-\gamma^{\mathrm{a}}$ mortality rate, $1-\omega^{\mathrm{a}}$ probability of economic ageing.

Since this ageing scenario keeps the inflow of newborns constant and a larger number of them make it to their eighties or even nineties, the scenario also implies an increase in overall population size of 7.2 per cent. $^{7}$ According to official projections, the Swiss population is expected to largely remain constant in the long-run on account of a parallel decline in fertility. We suppress this part in order to observe the consequences of ageing in isolation. Instead, we compare the ageing scenario for different assumptions with regard to international capital mobility. For this purpose, we have calibrated the model with net foreign debt equal to zero. In a small open economy, the real interest rate is fixed on world markets. Any imbalance between domestic savings and investment is thus reflected in a change in the net foreign asset position. In a closed economy, the domestic real interest rate adjusts to maintain net foreign assets at zero. This

$5 \quad$ People in group 6 are not literally in their seventies. Strictly speaking, group 6 consists of all young and old agents who share the economic characteristics of people in their seventies. However, the mass of people in group 6 is equal to the total mass of people belonging to cohorts 70-79 who define the characteristics of group 6. See the discussion in Section 4.1 and, in particular, equations (30) and (33).

6 This last part corresponds to the ageing scenario in Kalemli-Ozcan, Ryder and Weil (2000) who discuss the implications of longevity in a model with a single mortality rate.

7 The absolute number of people in younger groups does not change. However, because of the increase in the overall population, the population shares of worker groups, shown on the third line in Table 3, are now smaller. 
second scenario is interesting as ageing is a worldwide phenomenon that might lead to a decline in the real interest rate. ${ }^{8}$

This ageing scenario highlights the life-cycle properties of the model quite clearly. We first turn to the open economy case. Table 4 column 4 reports the long-run effects in the baseline scenario. With a constant real interest rate, the capital labour ratio and gross wages per efficiency unit of labour remain constant as well. Ageing results in a larger number of old people, which contributes to a larger population. In the absence of an offsetting decline in fertility, the mass of younger age groups remains almost unchanged, leading to a largely constant workforce and GDP. By assumption, the increased number of retirees erodes pensions per capita to an extent that keeps the pensions-to-GDP ratio constant. Note, however, that the increase in overall population by about $7 \%$ inflates government consumption and thereby necessitates a moderate increase in the wage tax by 1.3 percentage points. ${ }^{9}$

The higher tax erodes the net wage and thereby discourages hours worked at the intensive margin of labour supply. ${ }^{10}$ This in itself would lead to lower employment and output. However, the large reduction in per capita pensions makes retirement less attractive compared to continued work. With $x$ rising from .45 to .57 , postponed retirement raises aggregate labour supply at the extensive margin. For this reason, the aggregate workforce expands by $2.3 \%$. This translates into a small increase in effective labour supply for two reasons. Firstly, active people work fewer hours, and secondly the expansion of the work force occurs with the least productive people in age group 5 . The net effect is a small increase in effective labour supply which is accompanied by an equally small increase in capital to keep the capital labour ratio constant. ${ }^{11}$

$8 \quad$ For example, computations by Börsch-Supan, Ludwig and Winter (2004, p.27) yield a decline in the return to capital by roughly one percentage point as a result of worldwide ageing.

9 Pension spending is a constant ratio of GDP, $p N^{R}=p_{0} Y$, while public consumption is constant per capita, $G=g N$. Dividing (A.3) by the wage sum yields $t^{W}=p_{0} /(1-\alpha)+N g /(w L)$. With $w L$ largely constant, the wage tax rate must rise due to increasing $N$.

10 The appendix introduces endogenous labour supply by allowing for variable hours worked and variable retirement. In age group 5, agents choose the "retirement date" $x$ which determines the participation rate in this group. Average income $y^{5}=x\left(1-t^{W}\right) w \theta^{5} l^{5}+(1-x) p$ thus reflects the extensive margin of labour supply.

11 Jaag, Keuschnigg and Keuschnigg (2007) emphasise the life-cycle labour supply and unemployment incidence of younger and older age groups of workers as a result of pension reform. These authors also introduce an explicite welfare analysis and report the intergenerational redistribution as well as aggregate welfare consequences of policy reform. 
Table 4:

Long-run impact of ageing

\begin{tabular}{ll|rrr}
\hline Key Macro Variables in \% & \multicolumn{1}{c}{ Closed } & Open & Open $^{\dagger}$ \\
\hline$r$ & real interest* (0.050) & 0.040 & 0.050 & 0.050 \\
$D^{f} / Y$ & net foreign assets GDP ratio* $(0.000)$ & 0.000 & 0.710 & 0.864 \\
$x$ & retirement date* (0.450) & 0.632 & 0.569 & 0.493 \\
$t^{W}$ & Contribution rate* (0.308) & 0.304 & 0.321 & 0.325 \\
\hline$p$ & pension per capita & -8.469 & -17.737 & -22.060 \\
$\left(1-t^{W}\right) w$ & net wage & 4.444 & -1.918 & -2.488 \\
$l$ & labour supply & 1.754 & -0.772 & -1.003 \\
$N^{W}$ & workers & 3.519 & 2.297 & 0.831 \\
$N^{R}$ & retirees & 19.274 & 23.250 & 28.019 \\
$L^{D}$ & employment (effective) & 5.150 & 1.390 & -0.222 \\
$K$ & capital stock & 17.057 & 1.390 & -0.222 \\
$Y$ & gross dom.prod, GDP & 9.173 & 1.390 & -0.222 \\
$C$ & consumption per capita & -0.522 & -1.582 & -2.427 \\
$A$ & assets per capita & 8.120 & 21.953 & 25.862 \\
\hline
\end{tabular}

Notes: Pension/GDP ratio and public consumption per capita constant.

$\%$ Per cent changes relative to ISS.

*) Absolute values, initial values in brackets.

$\dagger$ ) Simulation with $\varepsilon^{\mathrm{R}}=0.3$.

The last line in Table 4 clearly demonstrates the life-cycle savings response. When people expect a much reduced pension from the PAYG system $(-18 \%)$, they must increase their savings for retirement substantially even though the interest rate remains constant. Assets per capita increase by $22 \%$. Since higher survival rates among older agents swell the population size by about $7.2 \%$, aggregate assets would grow by roughly $30 \%$. In the absence of domestic investment opportunities, this extra wealth is invested abroad and leads to a net foreign asset position of $71 \%$ of GDP in the long-run. The additional asset income from abroad allows for an increase in aggregate consumption by roughly five and a half per cent, much higher than the increase in GDP. Consumption per capita, in contrast, falls by $1.6 \%$, the result of population growth due to ageing. In column 5 we report the results from a simulation using a retirement semi-elasticity of 0.3 , compared to 1 in the baseline case. Consequently, retirement is still postponed but to a smaller degree. The participation rate in age group 5 corresponding to workers in their 60 s rises only to $49 \%$, instead of $57 \%$. The weaker participation response leads to an overall decline in effective employment. Compared to column 4 , the increase in the number of workers is now overcompensated by the decrease in individual labour supply due to lower net wages.

Adjustment in the closed economy would be much different, as column "Closed" in Table 4 demonstrates. If the excess savings cannot be invested abroad, the real interest must decline, by one percentage point, to balance savings 
and investment. With production much more capital intensive, wages rise substantially by $4.4 \%$ in the long-run and thereby stimulate labour supply both on the intensive and extensive margins. People work more hours $(+1.8 \%)$, and they postpone retirement as work becomes more attractive relative to pension income. The expansion of effective employment in combination with higher capital intensity boosts the capital stock by $17.1 \%$ in the long-run, leading to an output gain of more than $9 \%$. Keeping the pension to GDP ratio constant, the country thus affords an overall increase in pension expenditure which substantially cushions the decline in per capita pensions of $8.5 \%$, instead of $17.7 \%$ in the open economy. The decline in the real interest rate in combination with a smaller decline in pensions per capita much reduces savings incentives, leading to a quite impressive long-run reduction in accumulated assets. Consequently, income from savings falls relative to the open economy scenario. Yet, aggregate consumption per capita now shrinks by only half a per cent, compared to $1.6 \%$ in the open economy. Higher disposable wages substitute for lower capital income.

\section{Conclusions}

The notion of economic ageing separates economic age from time since birth. Economic age is defined by a set of personal characteristics such as labour productivity, mortality, tastes, health, etc. that change less frequently over the life-cycle than periods since birth. People can retain their characteristics over several periods before they change as a result of ageing. Economic ageing occurs stochastically. Identifying a person with her biography, which is the sequence of discrete ageing events since birth, permits the analytic aggregation of a multitude of different generations into a low number of age groups. The EA model is thus a generalised OLG model.

In standard OLG models such as the most recent versions of the Auerbach and Kotlikoff (1987) framework, ageing occurs every period and the probability of dying is unity in the last period of life. The number of life-cycle periods corresponds to the number of age groups or cohorts. As Laitner (1990) has shown, typical models with 55 generations operate in a state space of 108 dimensions and are thus very expensive to implement. If ageing occurs less frequently, the number of age groups becomes smaller than the number of cohorts. In this paper, we approximated the life-cycle with eight age states. Counting as in Laitner (1990), the state space would be 14 instead of 108 dimensions. This low dimensionality greatly facilitates the empirical implementation and numerical solution of the model. First applications relating to a temporary baby boom and an 
increased longevity of life have demonstrated that the EA model is a much more powerful tool for quantitative empirical analysis of demographic change, compared to the perpetual youth model based on Blanchard (1985) and Yaari (1968) as well as the recent extension by Gertler (1998) with two age groups. These models are popular because of their analytical tractability and their simple empirical implementation. Yet they are quite limited when it comes to tracing out the life-cycle implications of certain shocks or investigating demographic change. The EA model lies between the Auerbach-Kotlikoff and Blanchard-Yaari models, allowing for analytical aggregation to a low number of age groups combined with a realistic modelling of the life-cycle and demographic change. It would be an interesting and important research topic to investigate how the choice of more or fewer states of economic age affects the quality of life-cycle approximation and the short- and long-term dynamic properties of the general equilibrium model.

\section{Acknowledgement}

Financial support from the Austrian Science Fund under project No. P14702 (Grafenhofer and M. Keuschnigg) and the Swiss National Science Foundation under project No. 1214-066928 (Jaag and C. Keuschnigg) is gratefully acknowledged. We appreciate useful comments on presentations at the University of St. Gallen, the annual meeting 2006 in Bayreuth and the meeting of the macroeconomics section 2006 in Vienna of the German Economic Association, the 61st International Atlantic Economic Conference 2006 in Berlin and the Austrian Economic Association 2006 in Vienna. We are particularly grateful for very detailed and constructive comments by three anonymous referees.

\section{References}

Altig, David, Alan J. Auerbach, Laurence J. Kotlikoff, Kent A. Smetters and Jan Walliser. 2001. "Simulating fundamental tax reform in the United States." American Economic Review 91: 574-595.

Auerbach, Alan J. and Lawrence J. Kotlikoff. 1987. Dynamic fiscal policy. Cambridge, MA: Cambridge University Press.

Baxter, Marianne and Robert King. 1993. "Fiscal policy in general equilibrium." American Economic Review 83: 315-334.

BFS. 2004. Die Schweizerische Arbeitskräfteerhebung (SAKE). Neuchatel: Bundesamt für Statistik.

Blanchard, Olivier J. 1985. "Debt, deficits and finite horizons." Journal of Political Economy 93: 223-247. 
Blundell, Richard, Monica Costa Dias and Costas Meghir. 2003. The impact of wage subsidies: a feneral equilibrium approach. Institute of fiscal Studies and Bank of Portugal.

Börsch-Supan, Axel. 2000. "Incentive effects of social security on sabor force participation: evidence in Germany and across Europe." Journal of Public Economics 78: $25-49$

Börsch-Supan, Axel, Alexander Ludwig and Joachim Winter. 2004. Aging, pension reform, and capital flows: a multi-country simulation model. University of Mannheim (MEA).

Buiter, Willem H. 1988. "Death, birth, productivity growth and debt neutrality." Economic Journal 98: 279-293.

Cass, David. 1965. "Optimum growth in an aggregate model of capital accumulation." Review of Economic Studies 32: 233-240.

Cremer, Helmuth and Pierre Pestieau. 2003. "The double dividend of postponing retirement." International Tax and Public Finance 10: 419-434.

Diamond, Peter. 1965. "National debt in a neoclassical growth model." American Economic Review 55: 1126-1150.

Farmer, Roger E. A. 1990. "Rince preferences." Quarterly Journal of Economics 105: 4360.

Gertler, Mark. 1999. "Government debt and social security in a life-cycle economy." Carnegie-Rochester Conference Series on Public Policy 50: 61-110.

Grafenhofer, Dominic, Christian Jaag, Christian Keuschnigg and Mirela Keuschnigg. 2006. "Probabilistic aging and overlapping generations." CESifo Working Paper No. 1680 , revised version.

Greenwood, Jeremy, Zvi Hercowitz and Gregory W. Huffman. 1988. "Investment, capacity utilization and the real business cycle". American Economic Review 78: 402417.

Hayashi, Fumio. 1982. "Tobin's marginal Q and average Q: a neoclassical interpretation." Econometrica 50: 213-224.

Heijdra, Ben J. 1998. "Fiscal policy multipliers: the role of monopolistic competition, scale economies, and intertemporal substitution in labour supply." International Economic Review 39: 659-696.

Heijdra, Ben J. and Ward E. Romp. 2005. Old people and the things that pass: shocks in a small open economy. University of Groningen.

Hubbard, Glenn and Kenneth L. Judd. 1987. "Social security and individual welfare: precautionary saving, borrowing constraints, and the payroll tax." American Economic Review 77: 630-646.

Immervoll, Herwig, Henrik Kleven, Claus Thustrup Kreiner und Emmanuel Saez. 2004. "Welfare reform in European countries: a microsimulation analysis." CEPR DP 4324. London.

Jaag, Christian, Christian Keuschnigg and Mirela Keuschnigg. 2007. "Pension reform, retirement and life-cycle unemployment: an analysis of pension reform in Austria." Discussion Paper IFF-HSG. University of St. Gallen.

Kalemli-Ozcan, Sebnem, Harl E. Ryder and David N. Weil. 2000. "Mortality decline, human capital investment and economic growth." Journal of Development Economics 62: 1-23.

Keuschnigg, Christian and Mirela Keuschnigg. 2004. "Aging, labor markets, and pension reform in Austria." FinanzArchiv 60: 359-392. 
King, Robert, Charles Plosser, and Sergio Rebelo. 1988. "Production, growth and business cycles: I. the basic neoclassical model." Journal of Monetary Economics 21: 195-232.

Koopmans, Tjalling C. 1965. "On the concept of optimal growth." In: The econometric approach to development planning. Amsterdam: North-Holland.

Laitner, John. 1990. "Tax changes and phase diagrams for an overlapping generations model." Journal of Political Economy 98: 193-220.

Mankiw, Gregory N. and David N. Weil. 1989. "The baby boom, the baby bust, and the housing market." Regional Science and Urban Economics 19: 235-258.

Ramsey, Frank. 1928. “A mathematical theory of saving." Economic Journal 38: 543-559.

Russell, Louise B. 1982. The baby boom generation and the economy. Washington, D.C.: Brookings Institution.

Saez, Emmanuel. 2002a. "Optimal income transfer programs: intensive versus extensive labor supply responses." Quarterly Journal of Economics 117: 1039-1073.

Samuelson, Paul A. 1958. "An exact consumption loan model of interest with or without the social contrivance of money." Journal of Political Economy 66: 467-482.

Smetters, Kent. 1999. "Ricardian equivalence: long-run Leviathan." Journal of Public Economics 73: 395-421.

Weil, David N. 2006. "Population aging.” NBER WP 12147.

Weil, Philippe. 1987. "Love thy children: reflections on the Barro debt neutrality theorem." Journal of Monetary Economics 19: 377-391.

Weil, Philippe. 1989. "Overlapping families of infinitely lived agents." Journal of Public Economics 38: 183-198.

Weil, Philippe. 1990. "Nonexpected utility in macroeconomics." Quarterly Journal of Economics 105: 29-42.

Weiss, Yoram. 1986. "The determinants of life cycle earnings: a survey." In: O. Ashenfelter and R. Layard (eds.) Handbook of labor economics I. Amsterdam, Elsevier, pp. 603-639.

Yaari, Menahem E. 1965. "Uncertain lifetime, life insurance, and the theory of the consumer." Review of Economic Studies 32: 137-150. 


\section{Appendix: Endogenous labour supply and retirement}

Consider age group $a=a_{R}$ with characteristics of people in their sixties. Assume that a fraction $x$ of this group is still active while the rest is retired. To retain symmetry, we assume that each agent receives a share $x$ of her labour income as wages and a share $1-x$ as an old age pension. A higher value of $x$ means postponed retirement and therefore a higher participation rate in this mixed group, which reflects the extensive margin of labour supply. We refer to $x$ as the retirement date since postponed retirement raises the share of wages in average labour income in that period. If actively employed, agents may work a variable number of $l^{a}$ hours reflecting the intensive margin. They trade off income and consumption against disutility of work, both on the intensive and extensive margins. A particularly simple and yet realistic approach is to exclude income effects. ${ }^{12}$ We thus assume an additively separable subutility over consumption and foregone leisure, $\bar{C}^{a} \equiv C^{a}-x \varphi\left(l^{a}\right)-\psi(x)$, where $\varphi(l)$ and $\psi(x)$ stand for convex disutility of work and postponed retirement, $\varphi^{\prime}, \psi^{\prime}>0$ and $\varphi^{\prime \prime}, \psi^{\prime \prime}>0$. Appropriately expanding (9) and (16) yields

$$
\begin{array}{rlrl}
\text { (i) } \quad V\left(A_{\alpha, t}^{a}\right) & =\max _{C_{\alpha, t}^{a}, l_{\alpha, t}^{a}, x_{\alpha, t}^{a}}\left[\left(\bar{C}_{\alpha, t}^{a}\right)^{\rho}+\gamma^{a} \beta \cdot\left(\bar{V}_{\alpha, t+1}^{a}\right)^{\rho}\right]^{1 / \rho} \text { s.t. } \\
(\text { ii }) & \gamma^{a} A_{\alpha, t+1}^{a} & =R_{t+1}\left[A_{\alpha, t}^{a}+\bar{y}_{\alpha, t}^{a}-\bar{C}_{\alpha, t}^{a}\right], \\
(\text { iii }) & \bar{C}_{\alpha, t}^{a} & =C_{\alpha, t}^{a}-x_{\alpha, t}^{a} \varphi\left(l_{\alpha, t}^{a}\right)-\psi\left(x_{\alpha, t}^{a}\right), \\
(\text { iv }) & \bar{y}_{\alpha, t}^{a} & =\max _{l_{\alpha, t}^{a}, x_{\alpha, t}^{a}}^{a}\left[x_{\alpha, t}^{a}\left[w_{t}^{a} l_{\alpha, t}^{a}-\varphi\left(l_{\alpha, t}^{a}\right)\right]+\left(1-x_{\alpha, t}^{a}\right) p_{t}-\psi\left(x_{\alpha, t}^{a}\right),\right. \\
(v) & y_{\alpha, t}^{a} & =x_{\alpha, t}^{a} w_{t}^{a} l_{\alpha, t}^{a}+\left(1-x_{\alpha, t}^{a}\right) p_{t}, \quad w_{t}^{a} \equiv\left(1-t^{W}\right) w_{t} \theta_{t}^{a} .
\end{array}
$$

A simple solution in three stages is possible. First, choose intensive and extensive labour supply to maximise effort-adjusted wage income in (A.1.iv), yielding

$$
w_{t}^{a}=\varphi^{\prime}\left(l_{t}^{a}\right), \quad w_{t}^{a} l_{t}^{a}-\varphi\left(l_{t}^{a}\right)-p_{t}=\psi^{\prime}\left(x_{t}^{a}\right) .
$$

Intensive labour supply depends exclusively on the current wage. The wage elasticity is determined by the curvature of $\varphi$. On the extensive margin, the chosen retirement date reflects the difference between utility adjusted wages and alternative pension income. The more generous pensions are relative to net wages,

Excluding income effects is quite common in the literature on optimal income taxation or on real business cycles. See, for example, Heijdra (1998) and Greenwood et al. (1988) in intertemporal macroeconomics, Saez (2002) and Immervoll et al. (2004) on optimal income taxation, and Cremer and Pestieau (2003) for modeling postponed retirement this way. 
the less people are inclined to incur the utility cost of postponed retirement, and the earlier they choose to retire. The share of wages in average labour income declines. Since wages and pensions are independent of history, labour supply and the retirement date are symmetric, $l_{\alpha, t}^{a}=l_{t}^{a}$ and $x_{\alpha, t}=x_{t}{ }^{a}$. The same holds for average and effort-adjusted labour income, $y_{t}^{a}$ and $\bar{y}_{t}^{a}$, respectively.

The second step solves the intertemporal problem in (A.1.i-ii) of allocating subutility $\bar{C}_{\alpha, t}^{a}$ over time exactly as in Proposition 3, except that $C$ is replaced by $\bar{C}$ and $y$ by $\bar{y}$. The solution of the first two steps gives optimal values for $\bar{C}$, $l$ and $x$. As a last step, it remains to compute optimal commodity consumption $C_{\alpha, t}^{a}$ by inverting (A.1.iii).

For all age groups $a<a^{R}$, the labour supply is reduced to the intensive dimension only. Consequently, $x=1$ in (A.1) and $\psi$ is a constant that is set to zero. Finally, age groups $a>a^{R}$ are fully retired. Endogenous labour supply also leads to modification of fiscal budget balance $t^{W} w_{t} L_{t}^{S}=p_{t} N_{t}^{R}+G_{t}$ and labour market equilibrium $L=L^{S}$ where

$$
L_{t}^{S}=\theta^{a^{R}} l_{t}^{a^{R}} \cdot x_{t} N_{t}^{a^{R}}+\sum_{a=1}^{a^{R}-1} \theta^{a} l_{t}^{a} N_{t}^{a}, \quad N_{t}^{R}=\left(1-x_{t}\right) N_{t}^{a^{R}}+\sum_{a=a^{R}+1}^{A} N_{t}^{a} .
$$

